\title{
artigo
}

Jurado, S.R.; Armelin, M.V.A.L.; Bassler, T.C.; Furlan, M.C.R.; Sanchez, A.; Valério da Silva, A.

Qualidade do ar interior em hospitais, aeronaves, navios de cruzeiros e o risco de transmissão aérea pelo Coronavírus

\section{Qualidade do ar interior em hospitais, aeronaves, navios de cruzeiros e o risco de transmissão aérea pelo Coronavírus}

Indoor air quality in hospital environments, aircraft, cruise ships and the risk of airborne transmission by Coronavirus Calidad del aire interior en hospitales, aviones, cruceros y el riesgo de transmisión aérea por Coronavirus

\section{RESUMO}

Os vírus representam causa comum de doença infecciosa adquirida em ambientes interiores, pois são facilmente transmitidos, especialmente em ambientes lotados e mal ventilados. Recentemente, o mundo vem passando pela pandemia da Síndrome Respiratória Aguda Grave do Coronavírus 2 (SARS-CoV-2). Esse estudo objetivou verificar na literatura internacional o risco de transmissão do vírus por aerossóis em ambientes climatizados, como hospitais, aeronaves e navios de cruzeiro. Tratou-se de revisão integrativa da literatura. A questão norteadora desta revisão foi: O Coronavírus pode se propagar pelo ar interior de ambientes climatizados como hospitais, aeronaves e navios e representar risco de transmissão para os usuários desses ambientes? A literatura pesquisada revelou que os aerossóis virais podem comprometer a qualidade do ar de ambientes interiores e facilitar a transmissão da SARS-CoV-2. Portanto, mais pesquisas devem ser realizadas no sentido de corroborar esses achados e também são necessárias medidas urgentes para melhorar a limpeza e higienização desses ambientes, além da verificação da renovação e filtragem do ar interior em salas de isolamento em hospitais, aeronaves e navios de cruzeiro.

DESCRIPTORS: Síndrome Respiratória Aguda Grave; Aerossóis; Coronavírus; Ar Interior.

\section{ABSTRACT}

Viruses represent a common cause of infectious disease acquired indoors, as they are easily transmitted, especially in crowded and poorly ventilated environments. Recently, the world has been experiencing the pandemic of the Severe Acute Respiratory Syndrome of Coronavirus 2 (SARS-CoV-2). This study aimed to verify in the international literature the risk of transmission of the virus by aerosols in acclimatized environments, such as hospitals, aircraft and cruise ships. It was an integrative literature review. The guiding question of this review was: Can the coronavirus spread through the indoor air of acclimatized environments such as hospitals, aircraft and ships and pose a risk of transmission to users of these environments? The researched literature revealed that viral aerosols can compromise indoor air quality and facilitate the transmission of SARS-CoV-2. Therefore, more research must be carried out to corroborate these findings and urgent measures are also needed to improve the cleanliness and hygiene of these environments, in addition to checking the renewal and filtering of indoor air in isolation rooms in hospitals, aircraft and cruise ships. DESCRIPTORES: Severe Acute Respiratory Syndrome; Aerosols; Coronavirus; Indoor Air.

\section{RESUMEN}

Los virus representan una causa común de enfermedades infecciosas adquiridas en interiores, ya que se transmiten fácilmente, especialmente en entornos abarrotados y con poca ventilación. Recientemente, el mundo ha estado experimentando la pandemia del Síndrome Respiratorio Agudo Severo Del Coronavirus 2 (SARS-CoV-2). Este estudio tuvo como objetivo verificar en la literatura internacional el riesgo de transmisión del virus por aerosoles en entornos aclimatados, como hospitales, aviones y cruceros. Fue una revisión bibliográfica integradora. La pregunta guía de esta revisión fue: ¿Puede el coronavirus propagarse a través del aire interior de entornos aclimatados como hospitales, aviones y barcos y presentar un riesgo de transmisión a los usuarios de estos entornos? La literatura investigada reveló que los aerosoles virales pueden comprometer la calidad del aire interior y facilitar la transmisión del SARS-CoV-2. Por lo tanto, se debe realizar más investigación para corroborar estos hallazgos y también se necesitan medidas urgentes para mejorar la limpieza e higiene de estos entornos, además de verificar la renovación y el filtrado del aire interior en salas de aislamiento en hospitales, aviones y cruceros.

DESCRITORES: Síndrome Respiratorio Agudo Grave; Aerosoles; Coronavirus; Aire em Interiores.

RECEBIDO EM: 27/03/2020 APROVADO EM: 28/03/2020 


\section{Sonia Regina Jurado}

Bióloga. Pós-Doutora em Saúde Pública/Qualidade do Ar Interior. Doutora em Fisiopatologia em Clínica Médica. Professora Associada IV da Universidade Federal de Mato Grosso do Sul (UFMS), Campus de Três Lagoas (CPTL), Curso de Enfermagem. ORCIDS: 0000-0002-7220-4083.

\section{Maria Vigoneti Araújo Lima Armelin}

Enfermeira, Doutora em Ciências. Professora Adjunta da Universidade Federal de Mato Grosso do Sul (UFMS), Campus de Três Lagoas (CPTL), Curso de Enfermagem. ORCIDS: 0000-0002-9862-1678.

\section{Thais Carolina Bassler}

Nutricionista. Doutora em Ciências. Professora Adjunta da Universidade Federal de Mato Grosso do Sul (UFMS), Campus de Três Lagoas (CPTL), Curso de Medicina e Enfermagem. ORCIDS: 0000-0001-6964-4492.

\section{Mara Cristina Ribeiro Furlan}

Enfermeira. Doutora em Saúde e Desenvolvimento do Centro-Oeste pela Universidade Federal de Mato Grosso do Sul (UFMS). Professora Adjunta da Universidade Federal de Mato Grosso do Sul (UFMS), Campus de Três Lagoas (CPTL), Curso de Enfermagem e Tutora do Programa de Educação Tutorial (PET) Enfermagem/UFMS/CPTL. ORCIDS: 0000-0003-3227-7074.

\section{Andrea Sanchez}

Bióloga. Doutora em Química Analítica. Professora Associada da Universidade Federal de Mato Grosso do Sul (UFMS), Campus de Três Lagoas (CPTL), Curso de Enfermagem. ORCIDS: 0000-0003-2875-662X.

\section{André Valério da Silva}

Enfermeiro. Doutor em Biologia Geral e Aplicada. Professor Adjunto da Universidade Federal de Mato Grosso do Sul (UFMS), Campus de Três Lagoas (CPTL), Curso de Medicina. ORCIDS: 0000-0003-0309-5394.

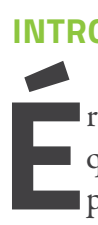
ar no interior dos ambientes é muito superior aos níveis do exterior ${ }^{(1)}$.

Ambientes internos tanto públicos quanto privados, incluindo residências, escritórios, escolas, locais de trabalho e sistemas de transporte contêm numerosos poluentes potencialmente prejudiciais à saúde. Recentemente, a exposição aos agentes biológicos, principalmente bactérias e fungos, despertou crescente interesse, porém estudos sobre presença de aerossóis virais no ar interior são escassos ${ }^{(2)}$.

Durante e após a doença, os vírus são eliminados em grande número nas secreções corporais, incluindo sangue, fezes, urina, saliva e líquido nasal ${ }^{(3)}$, o que pode contaminar superfícies e o ar. Quando uma pessoa infetada tosse, espirra ou fala, gotículas são espalhadas e podem ser inaladas ou atingirem as mucosas da boca, nariz ou olhos das pessoas que estão próximas ${ }^{(2)}$.

Os aerossóis, que são suspensões no ar

\section{Os Coronavírus}

são vírus de

RNA, da família

conhecidos por

causar doenças

respiratórias e

entéricas $^{(7)}$.
Coronaviridae,

de partículas sólidas ou líquidas, percorrem curtas distâncias (1-2 metros) antes do assentamento em superfícies onde os vírus podem permanecer viáveis por horas ou dias. A transmissão por gotículas não deve ser confundida com a transmissão aérea. Gotículas não permanecem suspensas no ar. Por outro lado, a transmissão aérea depende de núcleos de gotículas evaporadas (partículas pequenas $\leq 5 \mu \mathrm{m}$ ), contendo vírus, que podem permanecer suspensas no ar por longos períodos ${ }^{(4)}$.

Uma vez lançado em ambientes internos, o movimento e o destino dos vírus no ar é um processo complexo, envolvendo muitos fatores: o mecanismo e velocidade com que as gotículas são ejetadas da pessoa infectada, a concentração de vírus nas secreções respiratórias, presença de material particulado/matéria orgânica, fatores ambientais que afetam a inefetividade e viabilidade do vírus (por exemplo, temperatura e umidade), ventilação, aquecimento e sistema de ar condicionado ${ }^{(5,6)}$.

Os Coronavírus são vírus de RNA, da família Coronaviridae, conhecidos por causar doenças respiratórias e entéricas ${ }^{(7)}$. Um novo Coronavírus humano denomi- 


\section{artigo}

Jurado, S.R.; Armelin, M.V.A.L.; Bassler, T.C.; Furlan, M.C.R.; Sanchez, A.; Valério da Silva, A.;

Qualidade do ar interior em hospitais, aeronaves, navios de cruzeiros e o risco de transmissão aérea pelo Coronavírus

nado de Coronavírus 2 da Síndrome Respiratória Aguda Grave (SARS-CoV-2), anteriormente chamado $\mathrm{HCoV}-19$, surgiu em Wuhan, China, no final de 2019 e, agora está causando uma pandemia ${ }^{(8)}$.

Embora a origem do $\mathrm{HCoV}-19$ ainda esteja sendo investigada, as evidências atuais sugerem que a disseminação para seres humanos ocorreu por transmissão de animais selvagens vendidos ilegalmente no mercado atacadista de frutos do mar de Huanan, na China ${ }^{(9)}$.

Hospitais, em particular, são ambientes onde os aerossóis virais podem ser particularmente perigosos, uma vez que os pacientes tendem a ser especialmente propensos às infecções devido a preexistência de doenças. As principais vias de transmissão viral em hospitais são por via aérea, gotículas e contato direto ${ }^{(2)}$.

Em outros ambientes, como escolas e universidades, os principais meios de transmissão de agentes biológicos, como vírus, são: o contato direto, proximidade entre as bancadas dos alunos, falta de renovação do ar interior, falta de higienização dos aparelhos de ar condicionado e limpeza inadequada do mobiliário e piso das salas de aula ${ }^{(10,11)}$.

Ainda, há indícios da transmissão aérea do Coronavírus em aeronaves e navios de cruzeiros, pois, pacientes com SARS nesses meios de transporte contaminaram pessoas saudáveis durante as viagens ${ }^{(12,13)}$.

Os vírus têm sobrevivência prolongada em ambientes frios e secos, justamente os proporcionados por ambientes com ar condicionado ${ }^{(14,15)}$, além disso, uma pesquisa $^{(8)}$ revelou que o SARS-CoV-2 permaneceu mais estável em plástico e aço inoxidável do que em cobre e papelão, sendo detectado até 72 horas após a aplicação nessas superfícies. $\mathrm{O}$ mesmo estudo demonstrou que os Coronavírus têm a capacidade de sobreviver por muito tempo em aerossóis e superfícies.

Dada à maior viabilidade do SARS- $\mathrm{CoV}-2$ em ambiente frio e climatizado, além de poucos estudos sobre a transmissão desse vírus por meio de aerossóis e a crescente pandemia, o presente estudo objetivou verificar na literatura internacional se a contaminação ambiental do ar interior poderia explicar o risco de transmissão do vírus em ambientes hospitalares, aeronaves e navios de cruzeiros.

\section{METODOLOGIA}

Tratou-se de revisão integrativa da literatura. Esse método tem a finalidade de reunir e sintetizar resultados de pesquisas sobre um determinado tema ou questão, de maneira sistemática e ordenada, contribuindo para o aprofundamento do conhecimento do tema investigado ${ }^{(16)}$.

A revisão bibliográfica foi realizada no mês de março 2020 e incluiu publicações internacionais, no período de janeiro de 2003 a março de 2020. A escolha do ano inicial do recorte temporal deve-se ao aumento das discussões e da publicação referente à Síndrome Respiratória Aguda Grave (SARS) por Coronavírus.

A busca integrada foi realizada utilizando os seguintes descritores em inglês e os correspondentes em espanhol: [coronavirus, COVID-19, hospital]; [coronavirus, COVID-19, aircraft]; [coronavirus, COVID-19, cruise ship], unindo os mesmos com o conectivo "AND". Foram verificadas as fontes de busca Literatura Latino-Americana e do Caribe em Ciências da Saúde (LILACS) e PubMed.

A questão norteadora desta revisão in- tegrativa foi: O Coronavírus pode se propagar pelo ar interior de ambientes climatizados como hospitais, aeronaves e navios e representar risco de transmissão para os usuários desses ambientes?

Os critérios de inclusão foram: artigos e editoriais escritos no idioma inglês ou espanhol; estar disponível eletronicamente na íntegra; apresentar no título e/ou resumo, pelo menos, três dos descritores. Foram excluídas dissertações e teses sobre a referida temática e artigos que não estavam disponíveis gratuita e eletronicamente nas bases de dados estudadas.

Após a confirmação de que o artigo entraria no estudo, procedeu-se a leitura do mesmo para o preenchimento do roteiro de coleta de dados, que buscava investigar o ano de publicação, tipo do estudo, descrição da amostra e do ambiente estudado (hospital, aeronave, navio de cruzeiro) e principais achados.

\section{RESULTADOS E DISCUSSÃO}

Foram localizados 414 trabalhos referentes à temática pesquisada. Contudo, após exclusão de duplicatas e atendimento aos critérios de inclusão, foram utilizados 17 trabalhos (Figura 1) que estão listados no Quadro 1.

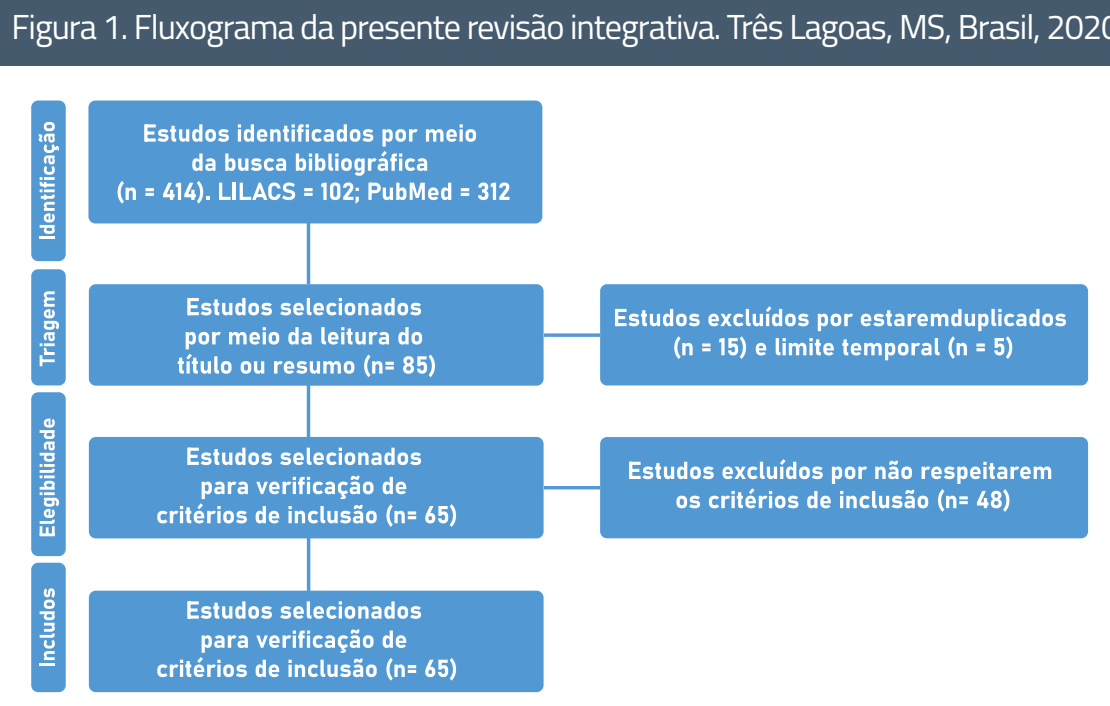

Adaptado de Moher D et al. The PRISMA Group. Preferred reporting items for systematic reviews. Plos Med. 2009; 6(7): e1000097(17). 
A fim de facilitar a compreensão dos resultados e discussão, os mesmos foram sumarizados nos seguintes tópicos: transmissão de Coronavírus em aeronaves, transmissão de Coronavírus em navios de cruzeiros, SARS e ambientes hospitalares.

\section{Quadro 1. Trabalhos incluídos na revisão integrativa referente à qualidade do ar interior e o risco de transmissão do Coronavírus em hospitais, aeronaves e navios de cruzeiro. Três Lagoas, MS, Brasil, jan/2003-mar/2020.}

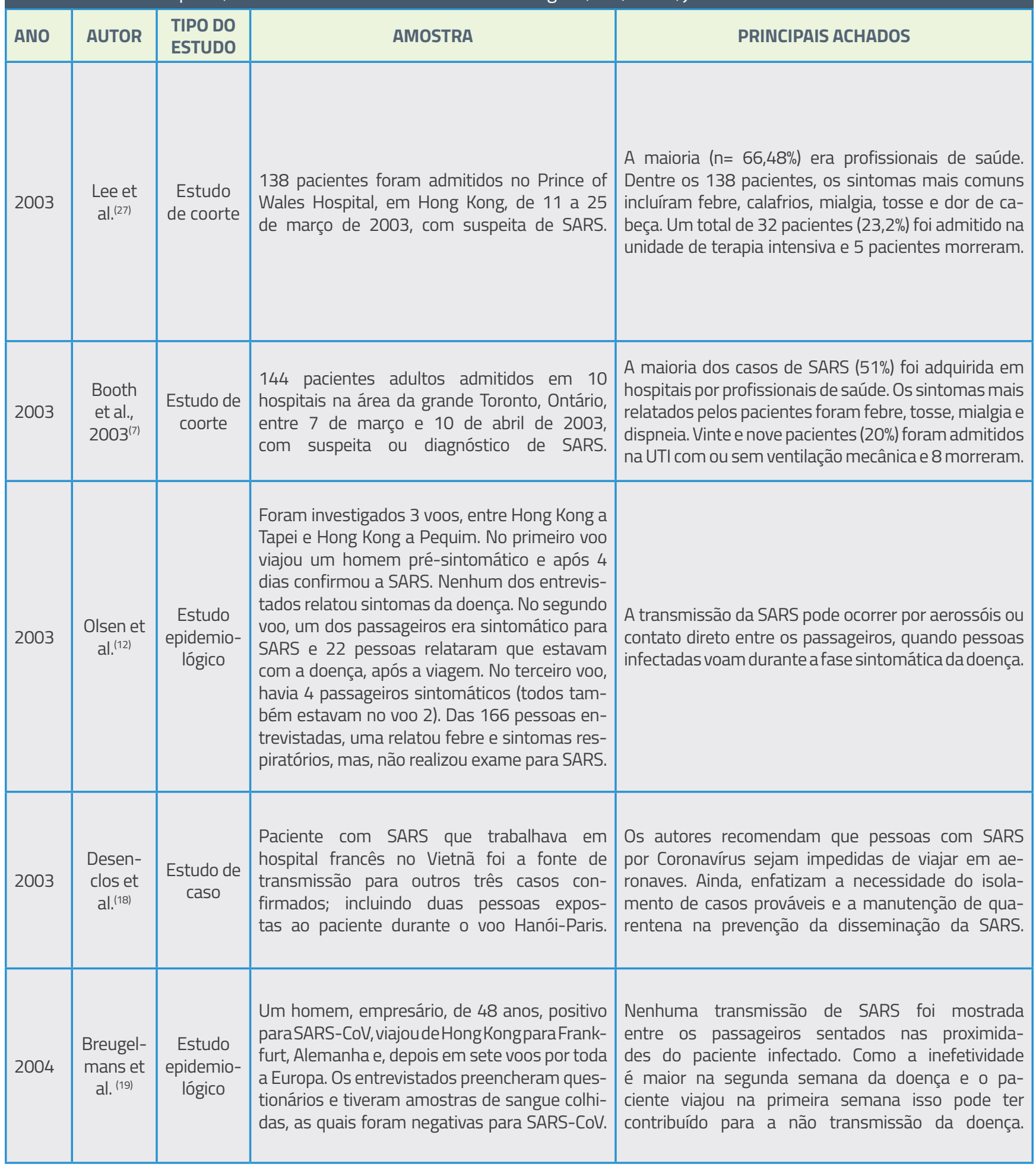




\begin{tabular}{|c|c|c|c|c|}
\hline 2005 & Li et al. (28) & $\begin{array}{l}\text { Estudo } \\
\text { retros- } \\
\text { pectivo }\end{array}$ & $\begin{array}{l}\text { Análise ambiental da enferma- } \\
\text { ria de um hospital, em Hong Kong, } \\
\text { que sofreu surto de SARS, em } 2003 .\end{array}$ & $\begin{array}{l}\text { Inspeções no local, medições da ventilação e sistema } \\
\text { de distribuição de ar foram verificadas, além de simu- } \\
\text { lações computacionais de dinâmica de fluidos para } \\
\text { analisar a dispersão de bioaerossóis na enfermaria do } \\
\text { hospital. A concentração de bioaerossóis na enferma- } \\
\text { ria parece ter sido fator causal para o surto de SARS. }\end{array}$ \\
\hline 2005 & $\begin{array}{l}\text { Booth et } \\
\text { al. }{ }^{(7)}\end{array}$ & $\begin{array}{l}\text { Estudo } \\
\text { ambiental } \\
\text { com cole- } \\
\text { tadas de } \\
\text { amostras } \\
\text { de ar } \\
\text { interior e } \\
\text { de super- } \\
\text { fícies }\end{array}$ & $\begin{array}{l}\text { Amostras ambientais foram coletadas de } \\
19 \text { salas para tratamento de SARS de } 4 \\
\text { centros de saúde de Toronto. Amostras fo- } \\
\text { ram testadas quanto à presença de SAR- } \\
\text { S-CoV pelo uso da reação em cadeia da } \\
\text { polimerase (PCR) e análise de cultura. }\end{array}$ & $\begin{array}{l}\text { Duas amostras de ar foram positivas do quarto ocupa- } \\
\text { do por um paciente com SARS, indicando a presença } \\
\text { do vírus no ar da sala. Além disso, superfícies apresen- } \\
\text { taram positividade para Coronavírus em salas ocupa- } \\
\text { das por pacientes com SARS (uma mesa de cabeceira } \\
\text { e um controle remoto de televisão) e no posto de en- } \\
\text { fermagem (na porta da geladeira para medicamentos). }\end{array}$ \\
\hline 2006 & $\begin{array}{l}\text { Vogt et } \\
\text { al. }(20)\end{array}$ & $\begin{array}{l}\text { Estudo } \\
\text { epide- } \\
\text { miológico }\end{array}$ & $\begin{array}{l}\text { Os cinco pacientes incluídos nessa pesquisa } \\
\text { adoeceram em fevereiro ou março de } 2003 \\
\text { após viajarem para uma região afetada pela } \\
\text { SARS. Quatro pacientes-índices foram confir- } \\
\text { mados laboratorialmente por infecção de SAR- } \\
\text { S-CoV. O quinto paciente foi caso-índice de um } \\
\text { surto em Toronto e morreu antes da realização } \\
\text { do exame. Nenhum dos } 312 \text { passageiros pes- } \\
\text { quisados que viajaram com os pacientes-índi- } \\
\text { ces apresentaram positividade para SARS-CoV. }\end{array}$ & $\begin{array}{l}\text { Embora o tamanho amostral tenha sido limita- } \\
\text { do, o trabalho sugere que o risco de transmissão de } \\
\text { SARS-CoV não é alto a bordo de aeronaves, mes- } \\
\text { mo entre passageiros sentados perto do paciente- } \\
\text {-índice em voos longos. É mais provável que a pro- } \\
\text { babilidade de transmissão seja determinada pela } \\
\text { infecciosidade do paciente-índice e não pelo ambiente } \\
\text { físico (por exemplo, aeronave, sala de aula ou hospital). }\end{array}$ \\
\hline 2013 & $\begin{array}{l}\text { La Rosa } \\
\text { et al. } .^{(2)}\end{array}$ & $\begin{array}{l}\text { Revisão } \\
\text { Bibliográ- } \\
\text { fica }\end{array}$ & $\begin{array}{l}\text { A grande maioria dos estudos enfo- } \\
\text { cou hospitais e outros serviços de saúde. }\end{array}$ & $\begin{array}{l}\text { Os vírus são causa bem conhecida de infecções } \\
\text { ocupacionais e nosocomiais nesses ambien- } \\
\text { tes. A falta de regulamentações, valores limi- } \\
\text { trofes e métodos padronizados de detecção de } \\
\text { vírus em ambientes internos dificultam a interpre- } \\
\text { tação dos resultados em ambientes hospitalares. }\end{array}$ \\
\hline 2020 & $\begin{array}{l}\text { Van Do- } \\
\text { remalen } \\
\text { et al. }{ }^{(8)}\end{array}$ & $\begin{array}{l}\text { Experi- } \\
\text { mental }\end{array}$ & $\begin{array}{l}\text { Experimentos envolvendo dois vírus (SARS- } \\
\text {-CoV-2 e SARS-CoV-1) em cinco condições } \\
\text { ambientais (aerossóis, plástico, aço inoxidável, } \\
\text { cobre e papelão). Foi utilizado um nebulizador } \\
\text { para criar os aerossóis ( }<5 \mu \text { m) e modelo de re- } \\
\text { gressão bayesiana para estimar as taxas de de- } \\
\text { caimento dos vírus nos aerossóis e superfícies. }\end{array}$ & $\begin{array}{l}\text { O SARS-COv- } 2 \text { foi detectado em aerossóis por até } 3 \\
\text { horas, até quatro horas em cobre, até } 24 \text { horas em } \\
\text { papelão e de } 2 \text { a } 3 \text { dias em plástico e aço inoxidável. A } \\
\text { estabilidade do SARS-CoV- } 2 \text { foi semelhante à do SAR- } \\
\text { S-CoV-1 nas circunstâncias experimentais testadas. }\end{array}$ \\
\hline 2020 & $\begin{array}{l}\text { Ong et } \\
\text { al. }^{(3)}\end{array}$ & $\begin{array}{l}\text { Estudo } \\
\text { microbio- } \\
\text { lógico de } \\
\text { amostras } \\
\text { de super- } \\
\quad \text { fícies }\end{array}$ & $\begin{array}{l}26 \text { amostras de superfícies foram cole- } \\
\text { tadas durante } 2 \text { semanas de sala de iso- } \\
\text { lamento, banheiro e antecâmara de } 01 \\
\text { paciente (C) com SARS-CoV- } 2 \text { antes da } \\
\text { limpeza de rotina e de } 2 \text { pacientes (A e B) } \\
\text { com a doença após a limpeza de rotina. }\end{array}$ & $\begin{array}{l}\text { Amostras da sala do paciente } \text { C se mostraram positi- } \\
\text { vas para SARS-CoV-2, incluindo ventiladores de saída } \\
\text { de ar da sala; vaso sanitário, pia e maçaneta da porta } \\
\text { do banheiro. O paciente } \mathrm{C} \text { teve comprometimento do } \\
\text { trato respiratório superior, sem pneumonia e, apresen- } \\
\text { tou } 2 \text { amostras de fezes positivas para SARS-CoV- } 2 \text {. }\end{array}$ \\
\hline 2020 & $\begin{array}{l}\text { Arashiro } \\
\text { et al. (21) }\end{array}$ & $\begin{array}{l}\text { Estudo de } \\
\text { caso }\end{array}$ & $\begin{array}{l}\text { Amostras de SARS-CoV-2 foram testadas } \\
\text { para dois tripulantes (uma garçonete e um } \\
\text { limpador de cozinha) de um navio de cruzeiro. }\end{array}$ & $\begin{array}{l}\text { A mulher, de } 35 \text { anos, do sul da Ásia, foi informa- } \\
\text { da que tinha resultado positivo para SARS-CoV-2 } \\
\text { no } 6^{\circ} \text { dia e transferida para o hospital. O homem, } \\
\text { de } 27 \text { anos, também do sul da Ásia, testou posi- } \\
\text { tivo para SARS-CoV-2 no } 5^{\circ} \text { dia e foi internado. }\end{array}$ \\
\hline
\end{tabular}




\begin{tabular}{|c|c|c|c|c|}
\hline 2020 & $\begin{array}{l}\text { Kakimoto et } \\
\text { al. }\end{array}$ & $\begin{array}{l}\text { Desenvol- } \\
\text { vimento } \\
\text { de método } \\
\text { matemático } \\
\text { para estimar } \\
\text { o número de } \\
\text { novos casos } \\
\text { diários no } \\
\text { navio. }\end{array}$ & $\begin{array}{l}\text { Navio com mais de } 3.700 \text { passageiros } \\
\text { a bordo com primeiro caso sintomá- } \\
\text { tico de SARS-CoV- } 2 \text { que embarcou } \\
\text { em } 25 \text { de janeiro de } 2020 \text { e, em } 9 \text { de } \\
\text { fevereiro, foram detectados } 20 \text { novos } \\
\text { casos da doença. As pessoas foram } \\
\text { mantidas em quarentena por } 14 \text { dias } \\
\text { no navio e após esse período foram de- } \\
\text { tectados mais de } 700 \text { casos da doença. }\end{array}$ & $\begin{array}{l}\text { As pessoas que desenvolverem sintomas de SAR- } \\
\text { S-CoV-2 enquanto estiverem a bordo de um } \\
\text { navio devem ser isoladas para limitar a trans- } \\
\text { missão a outros passageiros e tripulantes }\end{array}$ \\
\hline 2020 & $\begin{array}{l}\text { Mizumoto, } \\
\text { Chowel|(13) }\end{array}$ & $\begin{array}{l}\text { Estudo de mo- } \\
\text { delo matemá- } \\
\text { tico e dados } \\
\text { de incidência } \\
\text { de séries } \\
\text { temporais que } \\
\text { descreveram } \\
\text { a trajetória do } \\
\text { surto entre } \\
\text { passageiros } \\
\text { e membros } \\
\text { da tripulação } \\
\text { em navio com } \\
\text { surto de SAR- } \\
\text { S-CoV-2. }\end{array}$ & $\begin{array}{l}3.711 \text { pessoas a bordo do navio Dia- } \\
\text { mond Princess. Dois dias após o térmi- } \\
\text { no da quarentena programada de duas } \\
\text { semanas, um total de } 621 \text { pessoas } \\
\text { sintomáticas e assintomáticas apre- } \\
\text { sentou positividade para SARS-CoV- } 2 \text {. }\end{array}$ & $\begin{array}{l}\text { A transmissão de passageiro a passageiro dominou } \\
\text { a dinâmica de transmissão no navio. Os pesquisa- } \\
\text { dores estimaram diminuição substancialmente dos } \\
\text { casos de SARS-CoV-2, após o governo japonês im- } \\
\text { plementar um controle aprimorado de quarentena } \\
\text { com a permanência dos passageiros em suas cabines }\end{array}$ \\
\hline 2020 & $\begin{array}{l}\text { Mizumoto, } \\
\text { Kagaya, } \\
\text { Zarebski, } \\
\text { Chowell(23) }\end{array}$ & $\begin{array}{l}\text { Estudo epi- } \\
\text { demiológico } \\
\text { para estimar } \\
\text { o número de } \\
\text { assintomá- } \\
\text { ticos entre } \\
\text { pacientes } \\
\text { positivos para } \\
\text { SARS-CoV-2. }\end{array}$ & $\begin{array}{l}634 \text { casos foram confirmados entre } \\
3.063 \text { testados, sendo } 306 \text { sintomáti- } \\
\text { cos e } 328 \text { assintomáticos. A faixa etá- } \\
\text { ria mais acometida foi de } 70-79 \text { anos. }\end{array}$ & $\begin{array}{l}\text { Atualmente, não há evidências claras de que pes- } \\
\text { soas assintomáticas com SARS-CoV-2 possam } \\
\text { transmitir a doença, mas há evidências indicando } \\
\text { que uma parcela substancial de indivíduos infec- } \\
\text { tados com SARS-CoV-2 é assintomática. Os auto- } \\
\text { res estimaram } 17,9 \% \text { de assintomáticos entre in- } \\
\text { divíduos com resultado positivo para SARS-CoV- } 2\end{array}$ \\
\hline 2020 & $\begin{array}{l}\text { Wilson et } \\
\text { al. }{ }^{(22)}\end{array}$ & $\begin{array}{l}\text { Estudo epide- } \\
\text { miológico para } \\
\text { estimar o risco } \\
\text { de morta- } \\
\text { lidade por } \\
\text { SARS-CoV-2. }\end{array}$ & $\begin{array}{l}\text { Os autores utilizaram dados da Or- } \\
\text { ganização Mundial da Saúde (OMS) } \\
\text { para calcular estimativas do risco de } \\
\text { mortalidade pela SARS-CoV-2, em } \\
5 \text { de março de 2020, para } 4 \text { popula- } \\
\text { ções: China; China, excluindo a provín- } \\
\text { cia de Hubei; um grupo de } 82 \text { países, } \\
\text { territórios e áreas; e passageiros e } \\
\text { tripulação de um navio de cruzeiro. }\end{array}$ & $\begin{array}{l}\text { Os riscos de mortalidade foram de } 3,5 \% \text { na China; } 0,8 \% \\
\text { na China, excluindo a província de Hubei; } 4,2 \% \text { no gru- } \\
\text { po de } 82 \text { países, territórios e áreas e } 0,6 \% \text { para o navio } \\
\text { de cruzeiro. De todos os resultados, o menos genera- } \\
\text { lizável ó caso da China, que pode ser elevado devido } \\
\text { a casos leves não diagnosticados, escassez inicial de } \\
\text { kits de teste e risco elevado de morte devido às altas } \\
\text { demandas iniciais do sistema de saúde em Wuhan } \\
\text { No entanto, dadas às incertezas residuais, os auto- } \\
\text { res sugerem que as estimativas de risco de mortali- } \\
\text { dade por SARS-CoV-2 podem variar de } 0,25 \% \text { a 3,0\% }\end{array}$ \\
\hline 2020 & $\begin{array}{l}\text { Zhang et } \\
\text { al. (26) }\end{array}$ & $\begin{array}{l}\text { Estudo epide- } \\
\text { miológico para } \\
\text { projeção de } \\
\text { novos casos } \\
\text { de SARS- } \\
\text {-CoV-2 em } \\
\text { um navio de } \\
\text { cruzeiro para } \\
\text { um período de } \\
10 \text { dias. }\end{array}$ & $\begin{array}{l}\text { Até } 16 \text { de fevereiro de } 2020 \text {, foram } \\
\text { confirmados } 355 \text { casos com infecção } \\
\text { por SARS-CoV-2 no navio Diamond } \\
\text { Princess, em Yokohama, na China. }\end{array}$ & $\begin{array}{l}\text { O número provável de novos casos chegaria a } 1514 \\
\text { no décimo dia. No entanto, com a retirada dos pa- } \\
\text { cientes doentes do navio e o sistema de quarentena } \\
\text { adequado, o número total estimado de casos cumu- } \\
\text { lativos seria reduzido. Nesse estudo foi considerada a } \\
\text { transmissão de aerossóis com o SARS-CoV-2 pelo sis- } \\
\text { tema central de ar condicionado entre os passageiros }\end{array}$ \\
\hline
\end{tabular}




\section{Transmissão de Coronavírus em aeronaves}

Em 2003, foi publicado o primeiro estudo que apontou para uma provável transmissão de Coronavírus em uma aeronave, de uma pessoa infectada para passageiros localizados em sete fileiras à frente ${ }^{(12)}$.

$\mathrm{O}$ mesmo estudo demonstrou que a maior concentração de pessoas que foi infectada estava em poltronas à frente do paciente com Coronavírus do que atrás e apontou para o papel da tosse na transmissão, causando uma combinação de aerossol e propagação de pequenas gotículas.

As gotículas grandes de espirro podem ser propagadas por até 15 centímetros, enquanto os aerossóis $(<5 \mu \mathrm{m})$ percorrem de 1 a 2 metros. No caso do paciente com SARS que contaminou os passageiros das fileiras à frente, a disseminação pode ter ocorrido através de aerossóis ou ainda fômites (roupas e superfícies contaminadas), contato resultante do movimento dos passageiros mais próximos durante o voo e contato nas áreas ou filas de espera, imediatamente antes do embarque ou após o desembarque ${ }^{(12)}$. Outra pesqui$\mathrm{sa}^{(18)}$ também confirmou a transmissão de SARS por Coronavírus durante viagens em aeronaves, na França.

Porém, a literatura é controversa em relação à transmissão do Coronavírus durante voos comerciais. Em 2004, foi realizado um estudo para verificar se um paciente com SARS que viajou de Hong Kong para a Alemanha e mais sete países da Europa contaminou passageiros durante os voos. A pesquisa não detectou passageiros com SARS e afirmou que o grau de inefetividade da doença na primeira semana é mais baixo do que na segunda, o que coincidiu com o período de viagens do paciente ${ }^{(19)}$.

Ainda, outro trabalho realizado nos Estados Unidos com 5 passageiros-índices, ou sejam que possuíam SARS- $\mathrm{CoV}$ durante os voos e pesquisou 339 passageiros, dos quais 312 preencheram questionários e 127 coletaram amostras laboratoriais para SARS-CoV detectou que a sorologia foi negativa em todos os casos, demonstrando que não houve infecção por Coronavírus ${ }^{(20)}$.

$\mathrm{O}$ mesmo trabalho enfatizou que a probabilidade de transmissão foi determinada pela infecciosidade do paciente-índice e não pelo ambiente físico (por exemplo, aeronave, sala de aula ou hospital).

\section{Transmissão de Coronavírus em navios de cruzeiro}

No estudo de Arashiro ${ }^{(21)}$ participaram dois tripulantes de navio de cruzeiro com surto de SARS-CoV-2, sendo uma mulher, de 35 anos, garçonete e, um homem, de 27 anos que trabalhava como limpador de cozinha no navio. A garçonete e sua colega de quarto dividiram o banheiro com outras 2 pessoas que tiveram sintomas semelhantes anteriormente. A mulher foi detectada com SARS-CoV-2 no $6^{\circ}$ dia da doença e o homem no $5^{\circ}$ dia, ambos foram transferidos para o hospital para tratamento, mas, não evoluiu para pneumonia, o que pode representar o curso clínico em pessoas jovens e saudáveis.

O risco de mortalidade por SARS- CoV-2 é maior nas idades mais avançadas, quando o paciente já tem doença preexistente ou em lugares em que o sistema de saúde é deficitário. $\mathrm{O}$ risco de mortalidade por SARS-CoV-2 pode variar de $0,25 \%$ a $3,0 \%{ }^{(22)}$.

À medida que o vírus se espalha, é provável que ocorram casos mais leves ou assintomáticos de SARS-CoV-2 e, os profissionais de saúde devem estar cientes dessas manifestações clínicas ${ }^{(21,23)}$. A detecção de RNA viral não indica necessariamente infecciosidade, por isso, há a necessidade urgente de orientações para a detecção e gerenciamento da SARS$-\mathrm{CoV}-2$ leve $\mathrm{e}^{(21)}$.

Em 28 de fevereiro de 2020, um total de 705 casos de SARS-CoV-2 foi confirmado entre 4.061 passageiros e tripulantes de um navio de cruzeiro; 392 casos eram assintomáticos, 36 pessoas foram admitidas em unidades de terapia intensiva e 6 pacientes morreram ${ }^{(24)}$.

Outro surto de SARS-CoV-2 ocorreu no navio Diamond Princess, com 3.711 pessoas a bordo. O vírus foi detectado em um passageiro de Hong Kong, que embarcou no navio, em Yokohama, em 20 de janeiro de 2020 e, depois desembarcou em Hong Kong, em 25 de janeiro. Ele tinha tosse antes do embarque e foi diagnosticado com infecção da SARS-CoV-2, em 1 de fevereiro, em Hong Kong. O navio permaneceu em quarenta por 14 dias na costa do Japão e ao final desse período, aproximadamente 700 casos de SARS-CoV-2 foram confirmados entre passageiros e tripulantes ${ }^{(25)}$.

As vias de transmissão nos navios podem ter ocorrido por aerossóis distribuídos pelo sistema de ar condicionado central ${ }^{(26)}$ ou contato com superfícies infectadas pelo SARS-CoV-2, como: torneiras, maçanetas, pias e vasos sanitários dos banheiros dos navios e contato direto passageiro a passageiro ${ }^{(13)}$.

\section{SARS e ambientes hospitalares}

Os Coronavírus têm sido implicados em surtos nosocomiais com contaminação ambiental como via de transmissão, como é o caso SARS-CoV-2. No entanto, o modo de transmissão pelo ar interior e a extensão da contaminação ainda não é totalmente conhecida ${ }^{(3)}$.

Sabe-se que a SARS-CoV se espalha amplamente entre os profissionais de saúde em vários locais. Por exemplo, entre 138 casos de disseminação secundária e terciária em Hong Kong, 85 (62\%) ocorreram entre os profissionais de saúde ${ }^{(27)}$; dos 144 casos em Toronto, 73 (51\%) ocorreram entre os profissionais de saúde ${ }^{(7)}$. Portanto, a propagação de aerossóis do vírus da SARS pode ser responsável por esse tipo de transmissão.

Uma pesquisa revelou que dezesseis (24\%) de 66 estudantes de medicina desenvolveram SARS-CoV, subsequentemente, após ter entrado em contato ou não com paciente que estava infectado na enfermaria de um hospital em Hong Kong, porém, todos tinham estado nessa enfermaria. Esse resultado epidemiológico sugere claramente a transmissão da doença pelo ar interior ${ }^{(28)}$. 
Outro trabalho realizado com três pacientes com SARS-CoV-2 em salas de isolamento de infecções por via aérea, em Cingapura, tiveram amostras de superfície coletadas, antes e depois da limpeza. As amostras depois da limpeza das superfícies com 1000 ppm de dicloroisocianurato de sódio foram negativas. As amostras coletadas da sala de isolamento e banheiro de um dos pacientes antes da limpeza de rotina apresentaram positividade para SARS- CoV-2 nos ventiladores de saída de ar da sala, vaso sanitário, pia e maçaneta da porta do banheiro ${ }^{(3)}$.

Portanto, a contaminação viral nas fezes poderia ter infectado as superfícies do banheiro e ser uma via potencial de transmissão de contato, além disso, os aerossóis virais poderiam ter contaminado os ventiladores de saída de ar da sala, apontando uma transmissão aérea SARS-CoV-2.

Ong e colaboradores ${ }^{(3)}$ afirmaram que o tamanho da amostra era pequeno e que o volume de ar coletado representou apenas uma pequena fração do volume total e as trocas de ar na sala teriam diluído a presença de SARS-CoV-2 do ar nos ambientes limpos. Indubitavelmente, a limpeza das superfícies diminui a carga viral no ambiente, impedindo a transmissão da SARS-CoV-2.

Outra pesquisa também sugere a disseminação pelo ar do SARS-CoV no ambiente hospitalar. Um paciente com SARS que respirava silenciosamente, mas tossia, ocasionalmente, em um quarto de hospital contaminou o ar circundante com SARS-CoV, conforme demonstrado por experimentos realizados durante o surto de SARS no Canadá, no início de $2003^{(14)}$.

Ainda, segundo o mesmo estudo, amostras de superfície foram positivas para SARS-CoV, como cabeceira de cama e controle remoto de televisão usado pelo paciente com SARS. Além disso, a superfície da porta da geladeira de medicamentos no posto de enfermagem mostrou-se positiva para o vírus. Isso denota a necessidade de remover todas
Ong e

colaboradores $^{(3)}$

afirmaram que o

tamanho da amostra

era pequeno e que

o volume de ar

coletado representou

apenas uma pequena

fração do volume

total e as trocas de ar

na sala teriam diluído

a presença de SARS-

CoV-2 do ar nos

ambientes limpos.

Indubitavelmente,

a limpeza das

superfícies diminui

a carga viral no

ambiente, impedindo

a transmissão da

SARS-CoV-2. as luvas e higienizar as mãos ao sair do quarto dos pacientes com SARS.

Os dados fornecem a confirmação da geração de aerossóis virais por paciente com SARS, indicando a possibilidade de transmissão por gotículas e aerossóis no ar, o que enfatiza a necessidade de proteção respiratória adequada, bem como práticas estritas de limpeza e desinfecção de superfícies.

Assim, os profissionais de saúde que estão diretamente envolvidos no diagnóstico, tratamento e atendimento aos pacientes com SARS-CoV, correm o risco de se contaminarem com o vírus por contato direto ou por transmissão aérea. Além do risco biológico, vale lembrar que os profissionais da saúde que cuidam dos casos de SARS-CoV sofrem de angústia, devido à sobrecarga de trabalho, falta de equipamentos de proteção individual e falta de medicamentos específicos ${ }^{(29)}$.

Um estudo demonstrou que a contaminação ambiental por SARS-CoV de pacientes infectados atinge um pico entre 10 e 15 dias após o início sintomas, embora essa contaminação continue na fase convalescente em muitos $\operatorname{casos}^{(30)}$.

Portanto, em salas de isolamento em hospitais devem-se levar em conta as taxas de renovação do ar interior, o sistema de ventilação e climatização, a eficiência da filtragem do ar, assim como quaisquer procedimentos eletivos que possam resultar na geração de aerossóis de pacientes com SARS ${ }^{(14)}$.

Ademais, a detecção de vírus viáveis em amostras de ar ambiental é muito difícil. Métodos empregando impactadores de ar para coletar aerossóis são úteis, mas não são adequados para a detecção de baixas concentrações de vírus encontradas no ambiente clínico. Ainda, a renovação do ar, reduz bastante o RNA viral e número de cópias disponíveis para métodos de detecção( ${ }^{(5)}$.

Portanto, novas pesquisas devem ser incentivadas ao redor do mundo para compreender melhor a transmissão aérea do SARS-CoV-2 a fim de impedir a propagação da doença. 


\section{CONCLUSÃO}

O conhecimento dos mecanismos de transmissão aérea do SARS-CoV-2 permite entender melhor como impedir a propagação da doença. Nos ambientes hospitalares, melhorar a qualidade do ar interno, incluindo não apenas as enfermarias de isolamento, mas também as áreas comuns, pode impedir que es- ses ambientes sejam potenciais "centros de contágio".

Além disso, há necessidade da utilização de sistemas de filtragem e renovação do ar interior em ambientes como navios de cruzeiro, menor número e maior espaçamento das poltronas em aeronaves, bem como, melhor higienização das superfícies nesses ambientes, a fim de diminuir surtos e transmissão de doenças respiratórias, como a SARS-CoV-2.

Ademais, a colaboração internacional entre clínicos, pesquisadores e agências governamentais precisa continuar em um esforço para entender e controlar melhor essa doença infecciosa emergente, sobretudo, em relação à transmissão aérea do SARS-CoV-2.

\section{REFERÊNCIAS}

1. Flanningan B, Miller JD. Health implications of fungi indoor environments. Tokyo: Elsevier; 1994. chap 1, p.3-38.

2. La Rosa G, Fratini M, Libera SD, laconelli M, Muscillo M. Viral infections acquired indoors through airborne, droplet or contact transmission. Ann Ist Super Sanità. 2013; 49(2): 124-32.

3. Ong SWK, et al. Air, surface environmental, and personal protective equipment contamination by Severe Acute Respiratory Syndrome Coronavirus 2 (SARS-CoV-2) from a symptomatic patient. JAMA. 2020 Mar 4.

4. Rosa E, Melo Lisboa HM. Dispersão de aerossóis no sistema de tratamento de esgotos por lodo ativado na ETE Florianópolis SC. Rev Est Ambient. 2005; 7(1): 26-38.

5. Morawska L. Droplet fate in indoor environments, or can we prevent the spread of infection? Indoor Air. 2006; 16(5): 335-47. 6. Yau YH, Chandrasegan D, Badarudin A. The ventilation of multiple-bed hospital wards in the tropics: A review. Build Environ. 2011; 46: 1125-32.

7. Booth CM, et al. Clinical features and short-term outcomes of 144 patients with SARS in the greater Toronto area. JAMA. 2003; 289: 2801-9.

8. Van Doremalen N, et al. Aerosol and surface stability of SARS-CoV-2 as compared with SARS-CoV-1. N Engl J Med. 2020 Mar 17; 10.1056/NEJMc2004973.

9. Wang $D$, et al. Clinical characteristics of 138 hospitalized patients with 2019 novel coronavirus-infected pneumonia in Wuhan, China. JAMA. 2020; 323(11): 1061-9.

10. Jurado SR, Bankoff ADP. Indoor pollutants, microbial concentrations and thermal conditions influence student performance and health. IJBAS-IJENS. 2013; 13(4): 104-11.

11. Jurado SR, Bankoff ADP. Sanchez A. Indoor air quality in Brazilian universities. Int J Environ Res Public Health. 2014; 11: 7081-93.

12. Olsen SJ, et al. Transmission of the severe acute respiratory syndrome on aircraft. N Engl J Med 2003; 349(25): 2416-22.

13. Mizumoto K, Chowell G. Transmission potential of the novel coronavirus (COVID-19) onboard the diamond Princess Cruises Ship, 2020. Infect Dis Model. 2020; 5: 264-70.

14. Booth TF, et al. Detection of airborne severe acute respiratory system (SARS) coronavirus and environmental contamination in SARS outbreak units. J Infect Dis. 2005; 191: 1472-7.

15. Wolkoff P. Indoor air humidity, air quality, and health - An overview. Int J Hyg Envir Heal. 2018; 221(3): 376-90.

16. Mendes KDS, Silveira RCCP, Galvão CM. Revisão integrativa: método de pesquisa para a incorporação de evidências na saúde e na enfermagem. Texto Contexto - Enferm. 2008; 17(4): 758-64.
17. Moher D, et al. The PRISMA Group.

Preferred reporting items for systematic reviews. Plos Med. 2009; 6(7):

e1000097.

18. Desenclos J-C. Introduction of SARS in France, March-April, 2003. Emerg Infect Dis. 2004; 10(2): 195-200.

19. Breugelmans JG, et al. SARS Transmission and commercial aircraft. Emerg Infect Dis. 2004; 10(8): 1502-3.

20. Vogt TM. Risk of severe acute respiratory syndrome-associates coronavirus transmission on aboard commercial aircraft. J Travel Med. 2006; 5(13): 268-72.

21. Arashiro T, Furukawa K, Nakamura A. COVID-19 in 2 persons with mild upper respiratory tract symptoms on a cruise ship, Japan. Emerg Infect Dis. 2020; 26(6).

22. Wilson N, Kvalsvig A, Telfar Barnard L, Baker MG. Case-fatality estimates for COVID-19 calculated by using a lag time for fatality. Emerg Infect Dis. 2020; 26(6).

23. Mizumoto K, Kagaya K, Zarebski A, Chowell G. Estimating the asymptomatic proportion of coronavirus disease 2019 (COVID-19) cases on board the Diamond Princess cruise ship, Yokohama, Japan, 2020. Euro Surveill. 2020; 25(10): 1-5.

24. Ministry of Health. Labour and Welfare, Japan. Regarding COVID-19 cases on a cruise ship, 2020 Feb 26 [cited 2020 Mar 23]. https://www.mhlw.go.jp/stf/houdou/houdou_list_202002. htmlExternal Link.

25. Kakimoto $\mathrm{K}$, et al. Initial investigation of transmission of COVID-19 among crew members during quarantine of a cruise ship - Yokohama, Japan, February 2020. MMWR Morb Mortal Wkly Rep. 2020; 69(11): 312-13.

26. Zhang $S$, et al. Estimation of the reproductive number of novel coronavirus (COVID-19) and the probable outbreak size on the Diamond Princess cruise ship: A data-driven analysis. Int J Infect Dis. 2020; 93: 201-4.

27. Lee $\mathrm{N}$, et al. A major outbreak of severe acute respiratory syndrome in Hong Kong. N Engl J Med. 2003; 348: 1986-94.

28. Li Y, Huang X, Yu IT, Wong TW, Qian H. Role of air distribution in SARS transmission during the largest nosocomial outbreak in Hong Kong. Indoor Air. 2005; 15(2): 83-95.

29. Lai J, et al. Factors associated with mental health outcomes among health care workers exposed to coronavirus disease 2019. JAMA. 2020; 3(3): e203976.

30. Tang $P$, et al. Interpretation of diagnostic laboratory tests for severe acute respiratory syndrome: the Toronto experience. CMAJ. 2004; 170:47-54. 